\title{
A 12 week longitudinal study of microbial translocation and systemic inflammation in undernourished HIV-infected Zambians initiating antiretroviral therapy
}

Ashley Canipe ${ }^{1}$, Takondwa Chidumayo ${ }^{2}$, Meridith Blevins ${ }^{3,5}$, Michael Bestawros ${ }^{4}$, Jay Bala ${ }^{5}$, Paul Kelly ${ }^{2,6}$, Suzanne Filteau", Bryan E Shepherd ${ }^{3,5}$, Douglas C Heimburger ${ }^{5}$ and John R Koethe ${ }^{5,8^{*}}$

\begin{abstract}
Background: Undernourished, HIV-infected adults in sub-Saharan Africa have high levels of systemic inflammation, which is a risk factor for mortality and other adverse health outcomes. We hypothesized that microbial translocation, due to the deleterious effects of HIV and poor nutrition on intestinal defenses and mucosal integrity, contributes to heightened systemic inflammation in this population, and reductions in inflammation on antiretroviral therapy (ART) accompany reductions in translocation.

Methods: HIV-infected, Zambian adults with a body mass index $<18.5 \mathrm{~kg} / \mathrm{m}^{2}$ were recruited for a pilot study to assess the relationships between microbial translocation and systemic inflammation over the first 12 weeks of ART. To assess microbial translocation we measured serum lipopolysaccharide binding protein (LBP), endotoxin core lgG and IgM, and soluble CD14, and to assess intestinal permeability we measured the urinary excretion of an oral lactulose dose normalized to urinary creatinine (Lac/Cr ratio). Linear mixed models were used to assess within-patient changes in these markers relative to serum C-reactive protein (CRP), tumor necrosis factor-a receptor 1 (TNF-a R1), and soluble CD163 over 12 weeks, in addition to relationships between variables independent of time point and adjusted for age, sex, and CD4+ count.

Results: Thirty-three participants had data from recruitment and at 12 weeks: 55\% were male, median age was 36 years, and median baseline CD4+ count was 224 cells/ $/$ l. Over the first 12 weeks of ART, there were significant decreases in serum levels of LBP (median change $-8.7 \mu \mathrm{g} / \mathrm{ml}, \mathrm{p}=0.01$ ), TNF-a receptor $1(-0.31 \mathrm{ng} / \mathrm{ml}, \mathrm{p}<0.01)$, and CRP $(-3.5 \mathrm{mg} / \mathrm{l}, \mathrm{p}=0.02)$. The change in soluble CD14 level over 12 weeks was positively associated with the change in CRP $(p<0.01)$ and soluble CD163 $(p<0.01)$. Pooling data at baseline and 12 weeks, serum LBP was positively associated with CRP $(p=0.01)$, while endotoxin core IgM was inversely associated with CRP $(p=0.01)$ and TNF- $a$ receptor $1(p=0.04)$. The Lac/Cr ratio was not associated with any serum biomarkers.
\end{abstract}

Conclusions: In undernourished HIV-infected adults in Zambia, biomarkers of increased microbial translocation are associated with high levels of systemic inflammation before and after initiation of ART, suggesting that impaired gut immune defenses contribute to innate immune activation in this population.

Keywords: HIV infection, Antiretroviral therapy, Microbial translocation, Nutrition, Sub-Saharan Africa, Inflammation

\footnotetext{
* Correspondence: john.r.koethe@vanderbilt.edu

${ }^{5}$ Vanderbilt Institute for Global Health, Nashville, TN, USA

${ }^{8}$ Division of Infectious Diseases, Department of Medicine, Vanderbilt

University School of Medicine, A2200-MCN, 1161 21st Avenue South,

Nashville, TN, USA

Full list of author information is available at the end of the article
}

C Biomed Central

(c) 2014 Canipe et al.; licensee BioMed Central Ltd. This is an Open Access article distributed under the terms of the Creative Commons Attribution License (http://creativecommons.org/licenses/by/4.0), which permits unrestricted use, distribution, and reproduction in any medium, provided the original work is properly credited. The Creative Commons Public Domain Dedication waiver (http://creativecommons.org/publicdomain/zero/1.0/) applies to the data made available in this article, unless otherwise stated. 


\section{Background}

The epidemics of human immunodeficiency virus (HIV), chronic undernutrition, and food insecurity disproportionately affect Sub-Saharan Africa, and nutritional deficits contribute to increased morbidity and mortality among HIV-infected individuals in the region [1]. Undernourished (defined as body mass index $[\mathrm{BMI}]<18.5 \mathrm{~kg} / \mathrm{m}^{2}$ ) HIV-infected adults have a strikingly high early mortality rate after initiation of antiretroviral therapy (ART), over $25 \%$ in the first $90-180$ days in some studies, which is 4-6 fold higher than HIV-infected patients who are adequately nourished and is independent of the degree of immunosuppression (CD4+ T-cell count) [2-5]. The mechanism underlying this high early mortality is unknown and likely multifactorial, but prior studies have found heightened systemic inflammation to be a major risk factor $[6,7]$.

In studies of predominantly well-nourished individuals, microbial translocation has been proposed as an etiology of the persistent immune activation observed in patients with both untreated and treated HIV. However, there are few reports on the contribution of microbial translocation to the exceptionally high levels of systemic inflammation observed in patients with comorbid malnutrition and advanced HIV disease in resource-limited settings [8-10].

HIV infection depletes CD4+ cells in the gastrointestinal mucosa, particularly Th17 regulatory T-cells integral to defense against bacterial, fungal, and parasitic pathogens, and impairs tight junctions between epithelial cells, resulting in altered intestinal integrity and increased translocation of microbes from the intestinal lumen to the circulation [11-15]. Increased microbial translocation, as measured by circulating lipopolysaccharide (LPS; a component of the bacterial cell wall), anti-endotoxin antibodies, soluble CD14 (sCD14), and other biomarkers is associated with accelerated HIV disease progression and a higher risk of mortality $[16,17]$. Irrespective of HIV infection status, chronic undernutrition also impairs intestinal mucosal integrity and permits increased microbial translocation in a manner similar to advanced HIV infection, suggesting that the presence of both conditions in the same host may have compounding effects $[18,19]$.

We hypothesized that the high levels of systemic inflammation observed in undernourished adults with advanced HIV in sub-Saharan Africa are due in part to excessive microbial translocation, and reductions in microbial translocation following treatment initiation accompany a normalization of this inflammatory response. To test this hypothesis, we conducted a pilot study to measure intestinal permeability, microbial translocation, and systemic inflammation among undernourished, HIV-infected African adults starting ART.

\section{Methods}

This study was nested within a prospective, randomizedcontrolled trial of nutritional support to reduce early ART mortality (the Nutritional Support for African Adults Starting Antiretroviral Therapy [NUSTART] study trial registration \#PACTR201106000300631). Briefly, the NUSTART study was a randomized controlled trial of a lipid-based nutritional supplement, with or without additional vitamins and minerals, conducted in Zambia and Tanzania between 2011 and 2013 among HIVinfected, ART-eligible adults with clinical malnutrition (defined as a BMI $<18.5 \mathrm{~kg} / \mathrm{m}^{2}$ ) [20]. We enrolled a subset of trial participants from Zambia into a prospective cohort to evaluate markers of intestinal permeability, microbial translocation, and systemic inflammation from recruitment through the first 12 weeks of ART (inclusive of nutritional supplementation from enrollment to 6 weeks after starting ART).

Potentially eligible participants were evaluated by study staff at local health clinics and referred to University Teaching Hospital in Lusaka, Zambia for enrollment in the parent NUSTART trial and all study procedures. Inclusion criteria were at least 18 years of age, ARTnaïve (except for prior receipt of Prevention of Mother To Child Transmission regimens), ART-eligibility as determined by $\mathrm{CD} 4+$ T-cell count $<350$ cells $/ \mu \mathrm{l}$, BMI $<$ $18.5 \mathrm{~kg} / \mathrm{m}^{2}$, willingness to undertake intensive ART follow-up in the study clinic, and not pregnant.

Enrollment for this sub-study occurred from August 2012 through December 2012. Prior to starting ART and after 12 weeks of treatment, microbial translocation across the gut wall was assessed by measuring serum levels of LPS binding protein (LBP), endotoxin core IgG (EndoCAb IgG) and EndoCAb IgM (two antibodies previously shown to rise and fall, respectively, in response to circulating LPS levels) [21], and sCD14 using ELISA (Hycult Biotech, Uden, Netherlands). To assess systemic inflammation we measured serum levels of $\mathrm{C}$-reactive protein (CRP), soluble TNF- $\alpha$ receptor 1 , and soluble CD163 (sCD163, a marker of monocyte activation) using ELISA (R\&D Systems, Minneapolis, MN USA). Intestinal permeability was measured using the fractional absorption and urinary excretion of lactulose method (Lac/ $\mathrm{Cr}$ ratio). Patients ingested a $10 \mathrm{~g}$ dose of lactulose powder (Kristalose, Cumberland Pharmaceuticals, Nashville, TN, USA) dissolved in water, and urine was collected over a 5 hour period. The urine concentration of lactulose in $\mathrm{mmol} / \mathrm{l}$ was measured using an enzymatic, spectrophotometric technique and normalized to urine creatinine in mol/l (Oxford Biomedical Research, Rochester Hills, MI, USA) [22,23]. Participants who reported more than four bowel movements in the 24 hours preceding the enrollment were excluded from the lactulose urinary excretion testing because lactulose is a cathartic agent which 
could exacerbate diarrhea and contribute to volume depletion.

Participant clinical and demographic characteristics were expressed as percentages or as median values with interquartile range. The change in each biomarker from recruitment to 12 weeks of ART was assessed using the Wilcoxon signed rank test. Local polynomial regression fitting (loess) curves were fit to provide smoothed trends. We assessed the relationships between permeability, microbial translocation and inflammation biomarkers irrespective of time point (baseline or 12 weeks) using a linear mixed model with a random effect for the patient to account for correlation that may arise from measurements taken from the same patient, and adjusted for age, sex, and pre-treatment $\mathrm{CD} 4+\mathrm{T}$-cell count. The permeability and translocation biomarkers (LBP, EndoCAb IgG and IgM, sCD14, and urinary Lac/ $\mathrm{Cr}$ ratio) were log-transformed whereas inflammation biomarkers (CRP, TNF- $\alpha$ R1, and SCD163) remained on the unit scale. The primary analysis included the 33 participants evaluated at both recruitment and 12 weeks; a secondary analysis incorporated the recruitment visit data from 27 additional patients without 12 week data. Lastly, we assessed the relationship between the change in permeability and translocation biomarkers with the change in inflammation over the 12 weeks (i.e., withinpatient comparison) using ordinary least squares regression, with adjustment for the baseline biomarker values so that the effect measure is independent of baseline.

Analyses were performed using $\mathrm{R}$ (version 2.12.1; www.r-project.org). Analysis scripts are posted at http:// biostat.mc.vanderbilt.edu/wiki/Main/ArchivedAnalyses. The study was approved by the Institutional Review Board at Vanderbilt University and the Biomedical Research Ethics Committee of the University Teaching Hospital in Lusaka, Zambia, and all patients provided written informed consent.

\section{Results}

Sixty ART-naïve adults were recruited for this study between August and December 2012, and 33 returned at 12 weeks for the clinical assessment and laboratory studies. Of the 27 patients without week 12 data, one-third $(n=9)$ had never started ART, 2 died, 3 withdrew due to relocation, pregnancy, or acute illness, and 13 declined to return for week-12 measurements. Those included and excluded from the analysis did not differ according to age, sex, or pre-treatment BMI, serum hemoglobin, or CD4+ T-cell count ( $p>0.05$ for all). Among the 33 patients included in the follow-up analysis, 55\% were male and at enrollment, the median age was 36 years (interquartile range [IQR] 31-42), and the median CD4+ T-cell count was 224 cells/ $\mu$ l (IQR 151-256); all participants were undernourished according to $\mathrm{WHO}$ criteria (i.e. BMI $<18.5 \mathrm{~kg} / \mathrm{m}^{2}$ ), with a median BMI of $16.7 \mathrm{~kg} / \mathrm{m}^{2}$ (IQR 15.4-17.6). Table 1 shows the clinical characteristics of the 33 included cohort patients. Ten of the participants had fewer than 4 pairs of laboratory data and could not be included in some of the statistical models. Compared to the other 23 patients, those with fewer than 4 data pairs were similar by age, sex, hemoglobin or CD4+ T-cell count ( $p>0.05$ for all), but had lower pre-treatment BMI (15.6 versus $\left.17.4 \mathrm{~kg} / \mathrm{m}^{2} ; \mathrm{p}=0.02\right)$.

Participants reported a range of clinical complaints at enrollment including cough (66\%), subjective fever (41\%), pain with swallowing (13\%), abdominal pain (44\%), diarrhea (28\%), shortness of breath (25\%), and vomiting (9\%), but there were no significant differences in any of the baseline microbial translocation or inflammation biomarker levels between participants with and without these complaints (data not shown). Similarly, there were no significant differences in biomarker levels between those on therapy for tuberculosis (22\%) or with recent diarrheal illness (4\%) at enrollment.

From recruitment to 12 weeks of ART there was a significant decrease in serum levels of LBP (median change $-8.7 \mu \mathrm{g} / \mathrm{ml}, \mathrm{p}=0.01)$, TNF- $\alpha$ receptor $1(-0.31 \mathrm{ng} / \mathrm{ml}$, $\mathrm{p}<0.01)$, and CRP $(-3.5 \mathrm{mg} / \mathrm{l}, \mathrm{p}=0.02)$. An increase in

Table 1 Description of the cohort $(n=33)$

\begin{tabular}{|c|c|}
\hline \multicolumn{2}{|c|}{ Demographic and clinical characteristics } \\
\hline Female sex, n (\%) & $15(45 \%)$ \\
\hline Age (median years, IQR) & $36(31-42)$ \\
\hline $\begin{array}{l}\text { Baseline BMI } \\
\text { (median kg/m², IQR) }\end{array}$ & $16.7(15.4-17.6)$ \\
\hline $\begin{array}{l}\text { Week } 12 \mathrm{BMI} \\
\text { (median kg/m², IQR) }\end{array}$ & $17.6(16.5-19.0)^{*}$ \\
\hline $\begin{array}{l}\text { Baseline CD4+ count } \\
\text { (median cells/ } \mu \mathrm{L}, \mathrm{IQR} \text { ) }\end{array}$ & $224(151-256)$ \\
\hline $\begin{array}{l}\text { Week } 12 \text { CD4+ count } \\
\text { (median cells/ } \mu \mathrm{L}, \mathrm{IQR} \text { ) }\end{array}$ & $349(275-426)^{*}$ \\
\hline
\end{tabular}

Median serum and urine biomarker values pre-treatment and after 12 weeks of antiretroviral therapy, median (IQR)

\begin{tabular}{|c|c|c|}
\hline Biomarker & Recruitment & Week 12 of ART \\
\hline $\begin{array}{l}\text { Lipopolysaccharide binding } \\
\text { protein }(\mu \mathrm{g} / \mathrm{ml})\end{array}$ & $46.7(33.6-74.3)$ & $38.4(31.1-44.4)^{*}$ \\
\hline Soluble CD14 ( $\mu \mathrm{g} / \mathrm{ml})$ & $2.4(2.0-2.6)$ & $2.5(2.0-3.1)$ \\
\hline Endotoxin core lgM (units/ml) & $14.1(12.7-20.0)$ & $17.7(11.7-22.7)$ \\
\hline Endotoxin core lgG (units/ml) & $38.4(23.9-86.6)$ & $32.9(16.1-94.5)$ \\
\hline C-reactive protein (mg/l) & $18.3(4.5-64.8)$ & $6.4(3.8-19.7)^{*}$ \\
\hline TNF-a receptor 1 (ng/ml) & $1.3(0.8-2.4)$ & $1.0(0.6-1.3)^{*}$ \\
\hline Soluble CD163 (ng/ml) & $684(511-1022)$ & $531(376-1040)$ \\
\hline $\begin{array}{l}\text { Urine lactulose-to-creatinine } \\
\text { ratio }(\mathrm{mmol} / \mathrm{mol})\end{array}$ & $29.3(12.6-55.2)$ & $34.0(14.1-86.3)$ \\
\hline
\end{tabular}

Abbreviation: $A R T$ antiretroviral therapy, BMI body mass index, TNF- $a$ tumor necrosis factor- $a, I Q R$ interquartile range.

${ }^{*} p<0.05$ for change at 12 weeks. 
EndoCAb IgM antibody ( 0.6 units $/ \mathrm{ml}, \mathrm{p}=0.11)$ did not reach statistical significance. The Figure 1 shows the changes in the biomarkers from recruitment to 12 weeks of ART among all patients with paired samples, with smoothed curves fit to demonstrate overall trends, while the Additional file 1: Figure S1 shows the changes for inflammatory biomarkers as a function of changes in microbial translocation biomarkers.

Associations between pooled baseline and 12-week biomarkers of intestinal permeability, microbial translocation and inflammation were assessed using linear mixed models adjusted for age, sex, and baseline CD4+ T-cell count (Table 2). Serum LBP level was positively associated with CRP $(\mathrm{p}=0.01)$, and closely related to TNF- $\alpha$ receptor 1 and $\mathrm{sCD} 163(\mathrm{p}=0.08$ and $\mathrm{p}=0.13$, respectively). Serum EndoCAb IgM level (a circulating antibody shown in prior studies to rise in response to decreasing microbial translocation) was inversely associated with serum levels of CRP $(\mathrm{p}=0.01)$ and TNF- $\alpha$ receptor $1(p=0.04)$ [21]. Serum $s C D 14$ was associated with CRP $(\mathrm{p}<0.01)$ and $\mathrm{sCD} 163(\mathrm{p}<0.01)$, and closely related to TNF- $\alpha$ receptor $1(\mathrm{p}=0.07)$. We did not detect statistically significant relationships between Endo$\mathrm{CAb}$ IgG or the urine $\mathrm{Lac} / \mathrm{Cr}$ ratio and the inflammatory biomarkers. Results were similar when recruitment data from participants without a week 12 visit were included in the analysis.

In the linear models, the change in $\mathrm{sCD} 14$ from recruitment to 12 weeks was associated with the change in CRP $(\mathrm{p}=0.02)$ and $\mathrm{sCD} 163(\mathrm{p}=0.01)$ (Table 3). However, the change in EndoCAb IgM at 12 weeks was also positively associated with the change in $\mathrm{sCD} 163(\mathrm{p}=0.02)$, which was unexpected given the results from the pooled analyses. Changes in other translocation biomarkers over 12 weeks were not significantly associated with changes in inflammation.

Lastly, we assessed the relationship between the urinary Lac/Cr ratio, our biomarker of intestinal permeability, and the microbial translocation and inflammation biomarkers. We failed to detect any association of Lac/ $\mathrm{Cr}$ ratio with serum levels of LBP, EndoCAb IgM, EndoCAb IgG, or SCD14 in the linear mixed models, nor was the change in Lac/Cr over 12 weeks associated with the change in any of the translocation biomarkers over the same period. Similarly, the $\mathrm{Lac} / \mathrm{Cr}$ ratio was not associated with the measures of systemic inflammation.

\section{Discussion}

In this pilot study of undernourished adults starting ART in sub-Saharan Africa, serum levels of circulating CRP and other inflammatory biomarkers were markedly elevated prior to treatment initiation and after 12 weeks, and there was evidence that reductions in microbial translocation biomarkers, particularly LBP, accompanied reductions in inflammatory biomarkers. However, while we observed close associations between several pairs of translocation and inflammation biomarkers, there was marked heterogeneity both between and within participants. This suggests the hypothesis that microbial translocation is a primary driver of inflammation in
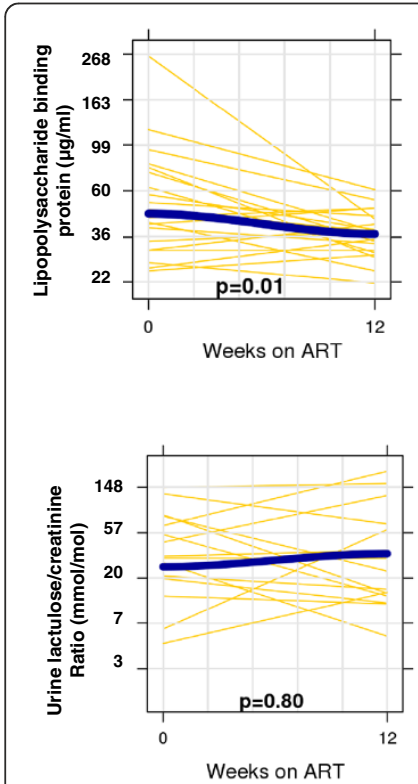
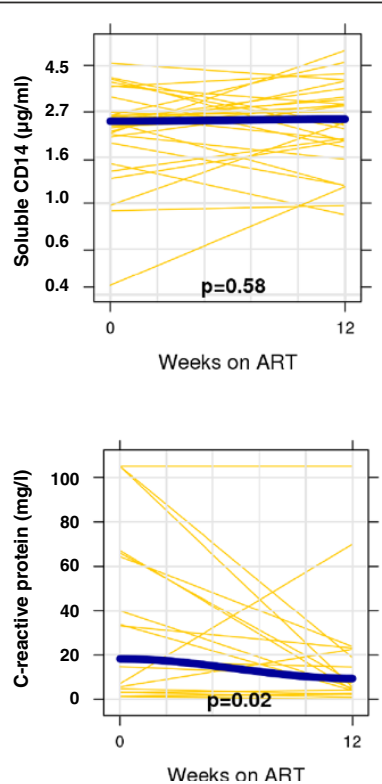
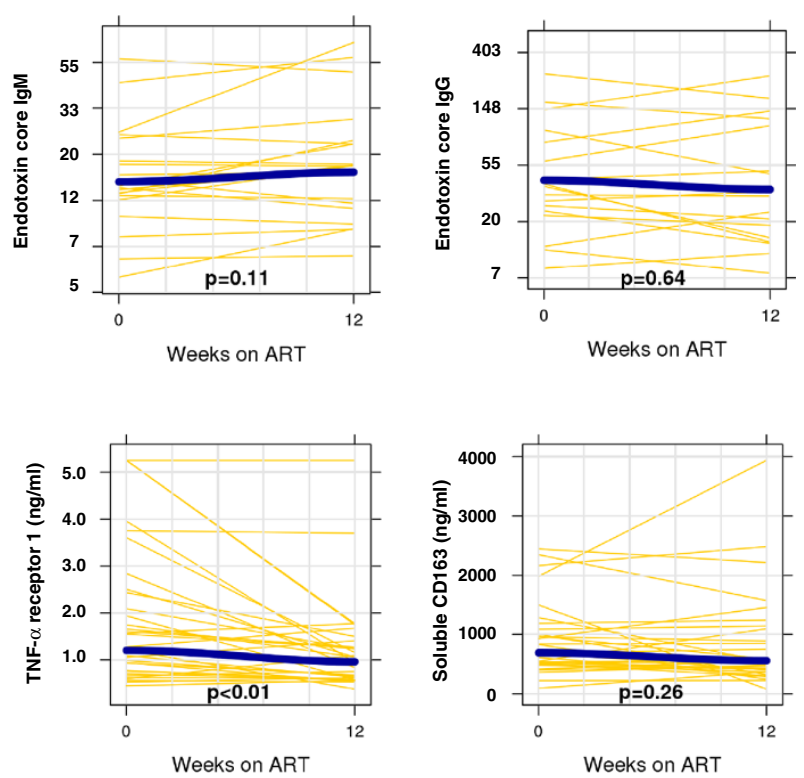

Figure 1 Changes in microbial translocation and inflammation biomarkers after 12 weeks of antiretroviral therapy. Yellow lines represent paired samples and the blue lines represent loess curves. As in the statistical models, the permeability and translocation biomarkers are log-transformed (with the $y$-axis labeled in the original scale) and the inflammation biomarkers are on the unit scale. Wilcoxon signed rank test assessed statistical significance. 
Table 2 Regression coefficients estimating the associations between biomarkers of microbial translocation and inflammation

\begin{tabular}{|c|c|c|c|}
\hline \multirow[b]{2}{*}{ Microbial translocation biomarkers } & \multicolumn{3}{|c|}{ Inflammation biomarkers } \\
\hline & C-reactive protein & Soluble CD163 & TNF-a receptor 1 \\
\hline & Estimate $(95 \% \mathrm{Cl})$ & Estimate $(95 \% \mathrm{Cl})$ & Estimate $(95 \% \mathrm{Cl})$ \\
\hline & p-value; model size & p-value; model size & p-value; model size \\
\hline \multirow[t]{2}{*}{ Lipopolysaccharide binding protein } & $28.9(8.6,49.1)$ & $169(-14,352)$ & $773(-11,1559)$ \\
\hline & $p=0.01 ; n=40$ & $p=0.13 ; n=40$ & $p=0.08 ; n=40$ \\
\hline \multirow[t]{2}{*}{ Endotoxin core IgM antibody } & $-25.7(-42.7,-8.7)$ & $-4.4(-164,155)$ & $-713(-1439,12)$ \\
\hline & $\mathbf{p}=0.01 ; n=38$ & $p=0.90 ; n=38$ & $p=0.04 ; n=40$ \\
\hline \multirow[t]{2}{*}{ Endotoxin core lgG antibody } & $-4.9(-17.1,7.4)$ & $39(-58,137)$ & $-324(-762,113)$ \\
\hline & $p=0.58 ; n=36$ & $p=0.76 ; n=36$ & $p=0.54 ; n=38$ \\
\hline \multirow[t]{2}{*}{ Soluble CD14 } & $44.7(21.3,68.2)$ & $595(289,902)$ & $620(8,1232)$ \\
\hline & $\mathrm{p}<0.01 ; n=40$ & $\mathrm{p}<0.01 ; \mathrm{n}=62$ & $p=0.07 ; n=62$ \\
\hline \multirow[t]{2}{*}{ Urine lactulose/creatinine ratio (linear) } & $0.22(-0.02,0.45)$ & $11(-118,140)$ & $141(-186,468)$ \\
\hline & $p=0.33 ; n=27$ & $p=0.68 ; n=38$ & $p=0.81 ; n=39$ \\
\hline
\end{tabular}

Results from linear mixed models pooling data across both recruitment and 12 weeks of ART. Models adjusted for age, sex, and baseline CD4+ T-cell count. Microbial translocation biomarkers (regression predictor) are log-transformed and inflammation biomarkers (regression outcome) remain on the unit scale. Model size represents total observations (recruitment and 12 week). Bold values represent statistically significant findings.

HIV-infected adults does not adequately capture what is likely a complex interplay of factors promoting innate immune activation in malnourished adults with advanced HIV disease.

Microbial translocation in undernourished, HIV-infected adults is likely due to the combined effects of HIV enteropathy, environmental enteropathy, and malnutrition on the intestinal mucosal barrier. HIV enteropathy generally occurs in advanced disease (e.g., CD4+ T-cell count $<200$ cells $/ \mu \mathrm{l})$ and is characterized by changes in villous morphology, absorption, and mucosal permeability $[24,25]$.
Mucosal T-cell depletion, particularly loss of the Th17 cells important for bacterial, fungal, and parasitic defense, in conjunction with impaired cellular tight junctions has been proposed as an underlying mechanism $[13,14,26]$. Environmental enteropathy is common in many tropical regions, including Zambia, and is morphologically similar to HIV enteropathy [27]. It is thought to result from a combination of recurrent, transient infections with pathogenic bacteria and altered intestinal microbiota resulting in chronic T-cell mediated enteric inflammation, malabsorption, impairment of mucosal integrity,

Table 3 Paired changes in microbial translocation and inflammation biomarkers over 12 weeks of ART

\begin{tabular}{|c|c|c|c|}
\hline \multirow[b]{2}{*}{ Microbial biomarkers (12 week change) } & \multicolumn{3}{|c|}{ Inflammation biomarkers (12 week change) } \\
\hline & C-reactive protein & Soluble CD163 & TNF-a receptor 1 \\
\hline & Estimate $(95 \% \mathrm{Cl})$ & Estimate $(95 \% \mathrm{Cl})$ & Estimate $(95 \% \mathrm{Cl})$ \\
\hline & p-value; model size & p-value; model size & p-value; model size \\
\hline \multirow[t]{2}{*}{ Lipopolysaccharide binding protein } & $-19(-72,33)$ & $13(-510,536)$ & $757(-1256,2769)$ \\
\hline & $p=0.45 ; n=20$ & $p=0.96 ; n=20$ & $p=0.44 ; n=20$ \\
\hline \multirow[t]{2}{*}{ Endotoxin core IgM antibody } & $-18(-61,25)$ & $436(72,800)$ & $-74(-1628,1480)$ \\
\hline & $p=0.38 ; n=19$ & $\mathbf{p}=\mathbf{0 . 0 2} ; n=19$ & $p=0.92 ; n=30$ \\
\hline \multirow[t]{2}{*}{ Endotoxin core $\lg G$ antibody } & $-1.2(-34,31)$ & $168(-86,423)$ & $-500(-1413,412)$ \\
\hline & $p=0.94 ; n=17$ & $p=0.18 ; n=17$ & $p=0.26 ; n=18$ \\
\hline \multirow[t]{2}{*}{ Soluble CD14 } & $38(7,69)$ & $697(183,1212)$ & $553(-208,1313)$ \\
\hline & $\mathbf{p}=\mathbf{0 . 0 2} ; n=20$ & $p=0.01 ; n=30$ & $p=0.15 ; n=20$ \\
\hline \multirow[t]{2}{*}{ Urine lactulose/creatinine ratio (linear) } & $-0.27(-22,21)$ & $154(-79,388)$ & $121(-86,329)$ \\
\hline & $p=0.97 ; n=11$ & $p=0.17 ; n=14$ & $p=0.22 ; n=14$ \\
\hline
\end{tabular}

Linear models estimate the relationships between 12-week changes in the log-transformed microbial translocation biomarkers (regression predictor) and 12-week changes in the inflammatory biomarkers (regression outcome) using ordinary least squares regression, adjusted for baseline biomarker values. Model size represents number of paired observations. Bold values represent statistically significant findings. 
and reduced expression of antimicrobial peptides [27-30]. Lastly, malnutrition is associated with hypoalbuminemia and bowel wall edema, impaired adaptive immune responses, and reduced mucosal integrity $[18,19,31]$.

Recent studies suggest that interventions to alter intestinal microbiota and mucosal cellular function in comorbid malnutrition and advanced HIV disease could provide clinical benefits for these patients, though much of this research remains at an early stage. There is evidence to suggest that probiotics can alter gastrointestinal tract microbiota, with beneficial effects on mucosal immunity [32]. In the HIV-infected population, administration of probiotics and other specialized nutritional products has led to modest improvements of CD4+ T-cell counts, reduced $\mathrm{CD} 4+\mathrm{T}$ cell activation, and fewer gastrointestinal disorders [33-36]. In the mouse model, glucagon-like peptide and probiotics improved intestinal integrity and reduced inflammation in obese mice [37]. Other promising non-human trials have demonstrated that vaccines may improve gastrointestinal tract immunity by recruiting IgA secreting plasma cells to the mucosa or decreasing the local HIV burden [38,39], and the use of a bovine serum immunoglobulin in adults with HIV enteropathy improved duodenal absorptive function and increased mucosal CD4+ T cell density [40].

While increased microbial translocation and systemic inflammation are both associated with poorer health outcomes in HIV infection, further research is needed to understand the clinical consequences in undernourished African patients and to determine if prior findings in US and European cohorts are applicable to this population. In a US cohort of ART-treated adults, higher serum levels of intestinal fatty acid binding protein and lower zonulin-1, both indicative of increased gut permeability, were associated with increased all-cause mortality [41]. In Italian HIV patients, serum LPS levels predicted disease progression independently of age, CD4+ T-cell count, viral load, or duration of infection, and higher circulating LPS levels after ART initiation were associated with greater $\mathrm{CD} 4+$ and $\mathrm{CD} 8+\mathrm{T}$-cell activation and poor CD4+ T-cell recovery $[16,42]$. Increased microbial translocation is also associated with dyslipidemia, insulin resistance, and increased risk of cardiovascular events in both HIV-infected and uninfected individuals [43-45], and persistently elevated CRP and other inflammation biomarkers predispose to fatal and nonfatal cardiovascular events $[46,47]$. However, conclusions regarding long-term health outcomes in African populations based on these studies are not warranted given differences in populations, background disease risk, methodology, and other factors. Further epidemiologic studies are needed to determine how very high levels of both microbial translocation and inflammation affect risk for cardiovascular, metabolic and other non-communicable diseases among HIV patients in sub-Saharan Africa.

While $\mathrm{SCD} 14$ has been posited as a marker of microbial translocation in prior studies of HIV-infected and uninfected populations, the association between sCD14 and inflammatory markers observed in our study and prior studies should be interpreted with caution [8,9,16,48-50]. A major uncertainty is whether high circulating sCD14 levels observed in HIV patients derive from intestinal or hepatic immune cells (e.g., intestinal monocytes or Kupffer cells exposed to LPS via the portal vein) and thus reflect increased intestinal microbial transit, or whether the increased $\mathrm{sCD} 14$ derives from immune cells in more distant tissues and should be classified as a general biomarker of systemic inflammation [51]. This uncertainty reduces the utility of sCD14 as an indicator of microbial translocation.

Our measurements of Lac/Cr ratio were not associated with any of our serum markers of microbial translocation, suggesting that intestinal permeability as measured by this method may not represent the same epithelial defects involved in increased microbial transit. In our cohort, the median baseline $\mathrm{Lac} / \mathrm{Cr}$ ratio value of $29.3 \mathrm{mmol} / \mathrm{mol}$ was approximately 3 -fold higher than in healthy controls in a prior study of European adults, but considerably lower than patients with active Crohn's disease [52]. Furthermore, we did not observe a clinically significant change in the Lac/Cr ratio over 12 weeks, which may indicate that while defenses against microbial translocation improved on ART, paracellular absorption from the gut lumen remained elevated. However, the use of the Lac/Cr ratio in HIV-infected, malnourished adults requires further validation given the chronic dehydration, potential HIV- and nutrition-related renal dysfunction, and reduced muscle mass present in this population.

Our pilot study was limited by small sample size and incomplete follow-up of some participants. The lack of both a non-malnourished, HIV-infected control group and a malnourished, uninfected control group made it impossible to explore the independent, and potentially synergistic, contributions of HIV and malnutrition to microbial translocation. The inverse association we observed between EndoCAb IgM and inflammation markers was expected based on prior sepsis studies showing that EndoCAb IgM levels vary inversely with serum endotoxin in the post-acute phase; however, we did not see any association between EndoCAb IgG and the outcomes of interest [21]. One possibility is that the EndoCAb IgG required adjustment for total IgG level, which is both high and variable in HIV infection. Future studies would also benefit from quantification of serum LPS or bacterial DNA and analysis of intestinal histology, rather than the surrogate markers of microbial translocation we used. Lastly, our study did not measure plasma HIV-1 RNA levels, which 
may have had independent pro-inflammatory effects and confounded our analysis, particularly if not all participants reached viral suppression after 12 weeks of treatment.

\section{Conclusions}

Our findings suggest that excessive microbial translocation across the bowel wall contributes to the high levels of systemic inflammation observed in undernourished adults with advanced HIV disease in sub-Saharan Africa. A high degree of translocation is likely due to the compounding effects of HIV enteropathy, environmental enteropathy, and malnutrition on mucosal barrier integrity and local immune defenses. Given the known adverse effects of heightened inflammation and microbial translocation on morbidity, mortality, and immune recovery after ART initiation, the development of interventions to improve gastrointestinal health in these patients may have important benefits for clinical outcomes.

\section{Additional file}

Additional file 1: Figure S1. Directional change in inflammation and microbial translocation biomarkers over 12 weeks among individual participants. Legend: Arrows represent the directional change in pairs of inflammation and microbial translocation biomarkers for each participant over the 12 weeks of follow-up.

\section{Competing interests}

The authors declare that they have no competing interests.

\begin{abstract}
Authors' contributions
AC participated in study design, acquisition of funding and data, as well as drafting and revising the manuscript. TC was involved with data acquisition and supervision of research group as well as manuscript revisions. M. Blevins and BS were involved in analysis and interpretation of data and manuscript revisions. M. Bestawros was involved with study design, acquisition of funding and data, and manuscript revisions. JB assisted with data acquisition and interpretation. PK, SF, and DH participated in study design, acquisition and interpretation of data, research group supervision, and manuscript revision. JK participated in study design, acquisition, analysis and interpretation of data, as well as drafting and revising the manuscript and supervising the
\end{abstract} research group. All authors read and approved the final manuscript.

\section{Acknowledgements \\ The authors would like to thank the NUSTART participants and study staff, the European \& Developing Countries Clinical Trials Partnership (EDCTP) for support of the NUSTART study, and the Zambian Ministry of Health for consistent support of research in the national HIV care and treatment program.}

\section{Funding sources}

This work was supported by the Vanderbilt Meharry Center for AIDS Research (NIH grant number P30 AI54999); the NIH Fogarty International Center, Office of the Director, National Institutes of Health, National Heart, Blood, and Lung Institute, and National Institute of Mental Health, through the Vanderbilt-Emory-Cornell-Duke Consortium for Global Health Fellows (grant number R25 TW009337); the National Center for Advancing Translational Sciences (CTSA award number UL1TR000445) and the European and Developing Countries Clinical Trials Partnership (grant IP.2009.33011.004). The trial nutritional supplements were prepared and supplied by Nutriset, Malauney, France.

Trial sponsor

London School of Hygiene and Tropical Medicine.

\section{Author details}

${ }^{1}$ Division of Gastroenterology, Hepatology and Nutrition, Vanderbilt University School of Medicine, Nashville, TN, USA. ${ }^{2}$ University Teaching Hospital, Lusaka, Zambia. ${ }^{3}$ Department of Biostatistics, Vanderbilt University School of Medicine, Nashville, TN, USA. ${ }^{4}$ Division of Cardiovascular Medicine, Vanderbilt University School of Medicine, Nashville, TN, USA. ${ }^{5}$ Vanderbilt Institute for Global Health, Nashville, TN, USA. ${ }^{6}$ Barts \& the London School of Medicine, London, UK. ' London School of Hygiene \& Tropical Medicine, London, UK. ${ }^{8}$ Division of Infectious Diseases, Department of Medicine, Vanderbilt University School of Medicine, A2200-MCN, 116121 st Avenue South, Nashville, TN, USA.

Received: 9 June 2014 Accepted: 24 September 2014 Published: 29 September 2014

\section{References}

1. Kelly P, Zulu I, Amadi B, Munkanta M, Banda J, Rodrigues LC, Mabey D, Feldman R, Farthing MJ: Morbidity and nutritional impairment in relation to CD4 count in a Zambian population with high HIV prevalence. Acta Trop 2002, 83:151-158

2. Stringer JS, Zulu I, Levy J, Stringer EM, Mwango A, Chi BH, Mtonga V, Reid S, Cantrell RA, Bulterys M, Saag MS, Marlink RG, Mwinga A, Ellerbrock TV, Sinkala M: Rapid scale-up of antiretroviral therapy at primary care sites in Zambia: feasibility and early outcomes. JAMA 2006, 296:782-793.

3. Zachariah R, Fitzgerald M, Massaquoi M, Pasulani O, Arnould L, Makombe S, Harries AD: Risk factors for high early mortality in patients on antiretroviral treatment in a rural district of Malawi. AIDS 2006, 20:2355-2360.

4. Gupta A, Nadkarni G, Yang WT, Chandrasekhar A, Gupte N, Bisson GP, Hosseinipour M, Gummadi N: Early Mortality in Adults Initiating Antiretroviral Therapy (ART) in Low- and Middle-Income Countries (LMIC): a systematic review and meta-analysis. PLoS One 2011, 6:e28691.

5. Koethe JR, Lukusa A, Giganti MJ, Chi BH, Nyirenda CK, Limbada MI, Banda Y, Stringer JS: Association between weight gain and clinical outcomes among malnourished adults initiating antiretroviral therapy in Lusaka, Zambia. J Acquir Immune Defic Syndr 2010, 53:507-513.

6. Koethe JR, Blevins M, Nyirenda C, Kabagambe EK, Shepherd BE, Wester CW, Zulu I, Chiasera JM, Mulenga LB, Mwango A, Heimburger DC: Nutrition and inflammation serum biomarkers are associated with 12-week mortality among malnourished adults initiating antiretroviral therapy in Zambia. $J$ Int AIDS Soc 2011, 14:19.

7. Kuller LH, Tracy R, Belloso W, De Wit S, Drummond F, Lane HC, Ledergerber B, Lundgren J, Neuhaus J, Nixon D, Paton NI, Neaton JD, INSIGHT SMART Study Group: Inflammatory and coagulation biomarkers and mortality in patients with HIV infection. PLoS Med 2008, 5:e203.

8. Brenchley JM, Price DA, Schacker TW, Asher TE, Silvestri G, Rao S, Kazzaz Z, Bornstein E, Lambotte O, Altmann D, Blazar BR, Rodriguez B, TeixeiraJohnson L, Landay A, Martin JN, Hecht FM, Picker LJ, Lederman MM, Deeks SG, Douek DC: Microbial translocation is a cause of systemic immune activation in chronic HIV infection. Nat Med 2006, 12:1365-1371.

9. Cassol E, Malfeld S, Mahasha P, van der Merwe S, Cassol S, Seebregts C, Alfano M, Poli G, Rossouw T: Persistent microbial translocation and immune activation in HIV-1-infected South Africans receiving combination antiretroviral therapy. J Infect Dis 2010, 202:723-733.

10. Brenchley JM, Douek DC: The mucosal barrier and immune activation in HIV pathogenesis. Curr Opin HIV AIDS 2008, 3:356-361.

11. Brenchley JM, Schacker TW, Ruff LE, Price DA, Taylor JH, Beilman GJ, Nguyen PL, Khoruts A, Larson M, Haase AT, Douek DC: CD4+ T cell depletion during all stages of HIV disease occurs predominantly in the gastrointestinal tract. J Exp Med 2004, 200:749-759.

12. Mehandru S, Poles MA, Tenner-Racz K, Horowitz A, Hurley A, Hogan C, Boden D, Racz P, Markowitz M: Primary HIV-1 infection is associated with preferential depletion of CD4+ T lymphocytes from effector sites in the gastrointestinal tract. J Exp Med 2004, 200:761-770.

13. Sankaran S, George MD, Reay E, Guadalupe M, Flamm J, Prindiville T, Dandekar S: Rapid onset of intestinal epithelial barrier dysfunction in primary human immunodeficiency virus infection is driven by an imbalance between immune response and mucosal repair and regeneration. J Virol 2008, 82:538-545.

14. Brenchley JM, Paiardini M, Knox KS, Asher Al, Cervasi B, Asher TE, Scheinberg P, Price DA, Hage CA, Kholi LM, Khoruts A, Frank I, Else J, Schacker T, Silvestri G, 
Douek DC: Differential Th17 CD4 T-cell depletion in pathogenic and nonpathogenic lentiviral infections. Blood 2008, 112:2826-2835.

15. Epple HJ, Schneider T, Troeger H, Kunkel D, Allers K, Moos V, Amasheh M, Loddenkemper C, Fromm M, Zeitz M, Schulzke JD: Impairment of the intestinal barrier is evident in untreated but absent in suppressively treated HIV-infected patients. Gut 2009, 58:220-227.

16. Marchetti G, Cozzi-Lepri A, Merlini E, Bellistri GM, Castagna A, Galli M, Verucchi G, Antinori A, Costantini A, Giacometti A, di Caro A, D'arminio Monforte A, ICONA Foundation Study Group: Microbial translocation predicts disease progression of HIV-infected antiretroviral-naive patients with high CD4+ cell count. AIDS 2011, 25:1385-1394.

17. Sandler NG, Wand H, Roque A, Law M, Nason MC, Nixon DE, Pedersen C, Ruxrungtham K, Lewin SR, Emery S, Neaton JD, Brenchley JM, Deeks SG, Sereti I, Douek DC, INSIGHT SMART Study Group: Plasma Levels of Soluble CD14 Independently Predict Mortality in HIV Infection. J Infect Dis 2011, 203:780-790.

18. Elia M, Goren A, Behrens R, Barber RW, Neale G: Effect of total starvation and very low calorie diets on intestinal permeability in man. Clin SCi (Lond) 1987, 73:205-210.

19. Welsh FK, Farmery SM, MacLennan K, Sheridan MB, Barclay GR, Guillou PJ, Reynolds JV: Gut barrier function in malnourished patients. Gut 1998, 42:396-401.

20. Rehman AM, Woodd S, Chisenga M, Siame J, Sampson G, Praygod G, Koethe JR, Kelly P, Filteau S: Appetite testing in HIV-infected African adults recovering from malnutrition and given antiretroviral therapy. Public Health Nutr 2014, 1-10. [published online May 1, 2014]. Epub ahead of print.

21. Barclay GR: Endogenous endotoxin-core antibody (EndoCAb) as a marker of endotoxin exposure and a prognostic indicator: a review. Prog Clin Biol Res 1995, 392:263-272.

22. Northrop CA, Lunn PG, Behrens RH: Automated enzymatic assays for the determination of intestinal permeability probes in urine. 1. Lactulose and lactose. Clin Chim Acta 1990, 187:79-87

23. Mullen A, Gosset L, Larke N, Manno D, Chisenga M, Kasonka L, Filteau S: The effects of micronutrient-fortified complementary/replacement food on intestinal permeability and systemic markers of inflammation among maternally HIV-exposed and unexposed Zambian infants. Br J Nutr 2012, 107:893-902.

24. Keating J, Bjarnason I, Somasundaram S, Macpherson A, Francis N, Price AB, Sharpstone D, Smithson J, Menzies IS, Gazzard BG: Intestinal absorptive capacity, intestinal permeability and jejunal histology in HIV and their relation to diarrhoea. Gut 1995, 37:623-629.

25. Kapembwa MS, Fleming SC, Sewankambo N, Serwadda D, Lucas S, Moody A, Griffin GE: Altered small-intestinal permeability associated with diarrhoea in human-immunodeficiency-virus-infected Caucasian and African subjects. Clin Sci (Lond) 1991, 81:327-334.

26. Nazli A, Chan O, Dobson-Belaire WN, Ouellet M, Tremblay MJ, Gray-Owen SD, Arsenault AL, Kaushic C: Exposure to HIV-1 directly impairs mucosal epithelial barrier integrity allowing microbial translocation. PLoS Pathog 2010, 6:e1000852.

27. Prendergast $A$, Kelly P: Enteropathies in the developing world: neglected effects on global health. Am J Trop Med Hyg 2012, 86:756-763.

28. Kelly P, Menzies I, Crane R, Zulu I, Nickols C, Feakins R, Mwansa J, Mudenda V, Katubulushi M, Greenwald S, Farthing M: Responses of small intestinal architecture and function over time to environmental factors in a tropical population. Am J Trop Med Hyg 2004, 70:412-419.

29. Veitch AM, Kelly P, Zulu IS, Segal I, Farthing MJ: Tropical enteropathy: a T-cell-mediated crypt hyperplastic enteropathy. Eur I Gastroenterol Hepatol 2001, 13:1175-1181.

30. Dhaliwal W, Bajaj-Elliott M, Kelly P: Intestinal defensin gene expression in human populations. Mol Immunol 2003, 40:469-475.

31. Koethe JR, Chi BH, Megazzini KM, Heimburger DC, Stringer JS: Macronutrient supplementation for malnourished HIV-infected adults: a review of the evidence in resource-adequate and resource-constrained settings. Clin Infect Dis 2009, 49:787-798.

32. Madsen $\mathrm{KL}$ : The use of probiotics in gastrointestinal disease. Can J Gastroenterol 2001, 15:817-822.

33. Hummelen R, Changalucha J, Butamanya NL, Koyama TE, Cook A, Habbema $J D$, Reid G: Effect of 25 weeks probiotic supplementation on immune function of HIV patients. Gut Microbes 2011, 2:80-85.

34. Hummelen R, Vos AP, van't Land B, van Norren K, Reid G: Altered hostmicrobe interaction in HIV: a target for intervention with pro- and prebiotics. Int Rev Immunol 2010, 29:485-513.
35. Gori A, Rizzardini G, Van't Land B, Amor KB, van Schaik J, Torti C, Quirino T, Tincati C, Bandera A, Knol J, Benlhassan-Chahour K, Trabattoni D, Bray D, Vriesema A, Welling G, Garssen J, Clerici M: Specific prebiotics modulate gut microbiota and immune activation in HAART-naive HIV-infected adults: results of the "COPA" pilot randomized trial. Mucosal Immunol 2011, 4:554-563.

36. Cahn P, Ruxrungtham K, Gazzard B, Diaz RS, Gori A, Kotler DP, Vriesema A, Georgiou NA, Garssen J, Clerici M, Lange JM, (BTE) Blinded Nutritional Study for Immunity and Tolerance Evaluation Study Team: The immunomodulatory nutritional intervention NR100157 reduced CD4+ T-cell decline and immune activation: a 1-year multicenter randomized controlled double-blind trial in HIV-infected persons not receiving antiretroviral therapy (The BITE Study). Clin Infect Dis 2013, 57:139-146.

37. Cani PD, Possemiers S, Van de Wiele T, Guiot Y, Everard A, Rottier O, Geurts L, Naslain D, Neyrinck A, Lambert DM, Muccioli GG, Delzenne NM: Changes in gut microbiota control inflammation in obese mice through a mechanism involving GLP-2-driven improvement of gut permeability. Gut 2009, 58:1091-1103.

38. Rainone $V$, Dubois $G$, Temchura $\vee$, Uberla K, Clivio A, Nebuloni M, Lauri E, Trabattoni D, Veas F, Clerici M: CCL28 induces mucosal homing of HIV-1specific IgA-secreting plasma cells in mice immunized with HIV-1 viruslike particles. PLoS One 2011, 6:e26979.

39. Fuller DH, Rajakumar P, Che JW, Narendran A, Nyaundi J, Michael H, Yager EJ, Stagnar C, Wahlberg B, Taber R, Haynes JR, Cook FC, Ertl P, Tite J, Amedee AM, Murphey-Corb M: Therapeutic DNA vaccine induces broad $T$ cell responses in the gut and sustained protection from viral rebound and AIDS in SIV-infected rhesus macaques. PLoS One 2012, 7:e33715.

40. Asmuth DM, Ma ZM, Albanese A, Sandler NG, Devaraj S, Knight TH, Flynn NM, Yotter T, Garcia JC, Tsuchida E, Wu TT, Douek DC, Miller CJ: Oral serum-derived bovine immunoglobulin improves duodenal immune reconstitution and absorption function in patients with HIV enteropathy. AIDS 2013, 27:2207-2217.

41. Hunt PW, Sinclair E, Rodriguez B, Shive C, Clagett B, Funderburg N, Robinson J, Huang Y, Epling L, Martin JN, Deeks SG, Meinert CL, Van Natta ML, Jabs DA, Lederman MM: Gut epithelial barrier dysfunction and innate immune activation predict mortality in treated HIV infection. J Infect Dis 2014. [published online April 21, 2014]. Epub ahead of print.

42. Marchetti G, Bellistri GM, Borghi E, Tincati C, Ferramosca S, La Francesca M, Morace G, Gori A, Monforte AD: Microbial translocation is associated with sustained failure in CD4+ T-cell reconstitution in HIV-infected patients on long-term highly active antiretroviral therapy. AIDS 2008, 22:2035-2038.

43. Lassenius MI, Pietilainen KH, Kaartinen K, Pussinen PJ, Syrjanen J, Forsblom C, Porsti I, Rissanen A, Kaprio J, Mustonen J, Groop PH, Lehto M, FinnDiane Study Group: Bacterial endotoxin activity in human serum is associated with dyslipidemia, insulin resistance, obesity, and chronic inflammation. Diabetes Care 2011, 34:1809-1815.

44. Manco M, Putignani L, Bottazzo GF: Gut microbiota, lipopolysaccharides, and innate immunity in the pathogenesis of obesity and cardiovascular risk. Endocr Rev 2010, 31:817-844.

45. Pedersen KK, Pedersen M, Troseid M, Gaardbo JC, Lund TT, Thomsen C, Gerstoft J, Kvale D, Nielsen SD: Microbial translocation in HIV infection is associated with dyslipidemia, insulin resistance, and risk of myocardial infarction. J Acquir Immune Defic Syndr 2013, 64:425-433.

46. Duprez DA, Neuhaus J, Kuller LH, Tracy R, Belloso W, De Wit S, Drummond F, Lane HC, Ledergerber B, Lundgren J, Nixon D, Paton NI, Prineas RJ, Neaton JD, INSIGHT SMART Study Group: Inflammation, coagulation and cardiovascular disease in HIV-infected individuals. PLoS One 2012, 7:e44454.

47. Triant VA, Meigs JB, Grinspoon SK: Association of C-reactive protein and HIV infection with acute myocardial infarction. J Acquir Immune Defic Syndr 2009, 51:268-273.

48. Landmann R, Knopf HP, Link S, Sansano S, Schumann R, Zimmerli W: Human monocyte CD14 is upregulated by lipopolysaccharide. Infect Immun 1996, 64:1762-1769.

49. Bas S, Gauthier BR, Spenato U, Stingelin S, Gabay C: CD14 is an acutephase protein. J Immunol 2004, 172:4470-4479.

50. Arias MA, Rey Nores JE, Vita N, Stelter F, Borysiewicz LK, Ferrara P, Labeta MO: Cutting edge: human $B$ cell function is regulated by interaction with soluble CD14: opposite effects on IgG1 and IgE production. J Immunol 2000, 164:3480-3486. 
51. Su GL, Goyert SM, Fan MH, Aminlari A, Gong KQ, Klein RD, Myc A, Alarcon WH, Steinstraesser L, Remick DG, Wang SC: Activation of human and mouse Kupffer cells by lipopolysaccharide is mediated by CD14. Am J Physiol Gastrointest Liver Physiol 2002, 283:G640-G645.

52. Dastych M, Dastych M Jr, Novotna H, Cihalova J: Lactulose/mannitol test and specificity, sensitivity, and area under curve of intestinal permeability parameters in patients with liver cirrhosis and Crohn's disease. Dig Dis Sci 2008, 53:2789-2792.

doi:10.1186/1471-2334-14-521

Cite this article as: Canipe et al: A 12 week longitudinal study of microbial translocation and systemic inflammation in undernourished HIV-infected Zambians initiating antiretroviral therapy. BMC Infectious Diseases 2014 14:521.

\section{Submit your next manuscript to BioMed Central and take full advantage of:}

- Convenient online submission

- Thorough peer review

- No space constraints or color figure charges

- Immediate publication on acceptance

- Inclusion in PubMed, CAS, Scopus and Google Scholar

- Research which is freely available for redistribution 